\title{
Coupling a gas chromatograph simultaneously to a flame ionization detector and chemical ionization mass spectrometer for isomer-resolved measurements of particle-phase organic compounds
}

Chenyang $\mathrm{Bi}^{1}$, Jordan E. Krechmer ${ }^{2}$, Graham O. Frazier ${ }^{1}$, Wen $\mathrm{Xu}^{2}$, Andrew T. Lambe ${ }^{2}$, Megan S. Claflin ${ }^{2}$, Brian M. Lerner ${ }^{2}$, John T. Jayne ${ }^{2}$, Douglas R. Worsnop ${ }^{2}$, Manjula R. Canagaratna ${ }^{2}$, Gabriel Isaacman-VanWertz ${ }^{1}$

${ }^{1}$ Department of Civil and Environmental Engineering, Virginia Tech, Blacksburg, Virginia, 24060, USA

${ }^{2}$ Aerodyne Research Inc, Billerica, Massachusetts, 01821, USA

Correspondence to: Gabriel Isaacman-VanWertz (ivw@vt.edu)

\section{Supporting Information}

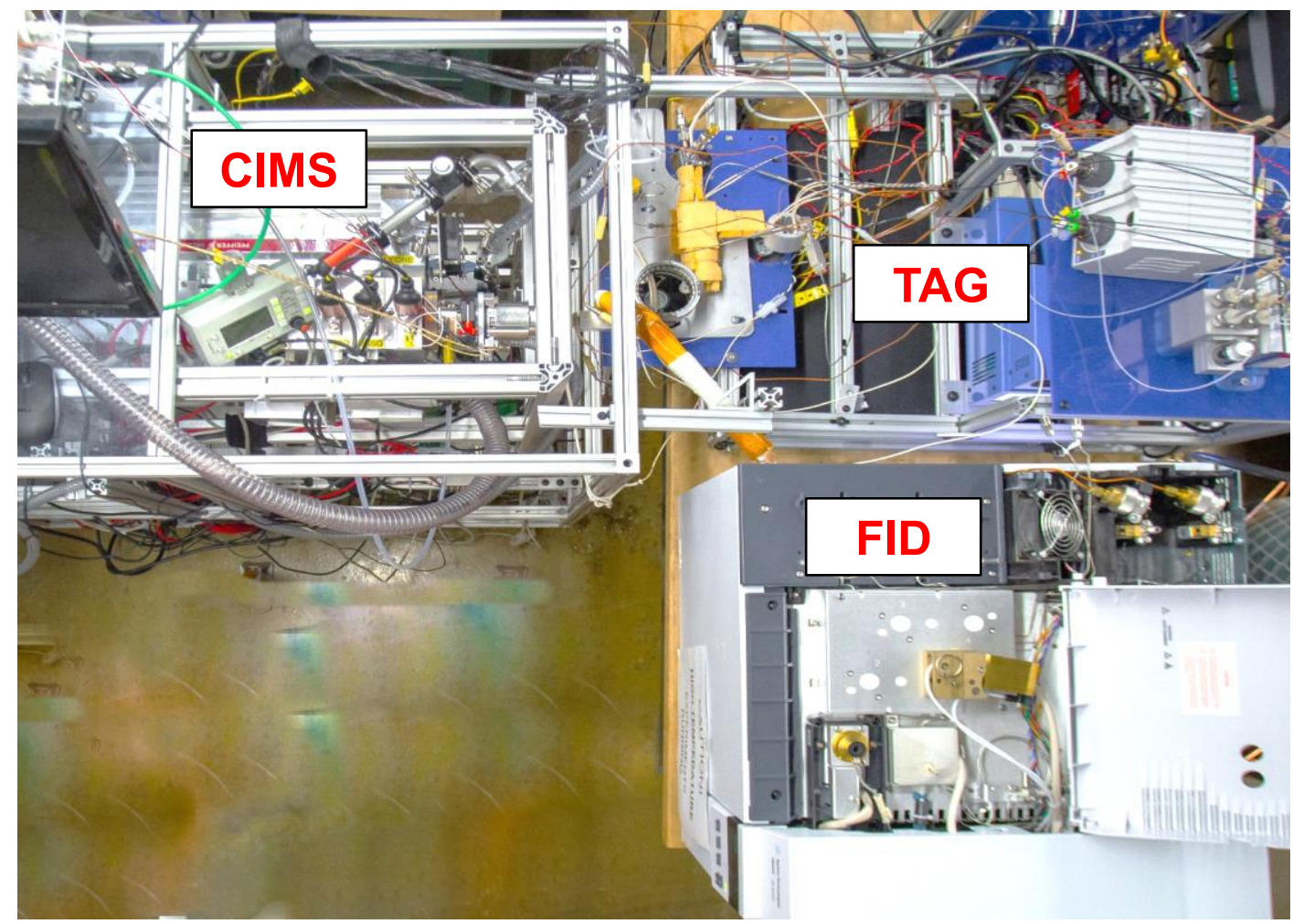

Figure S1. Plan view of the TAG-CIMS/FID 


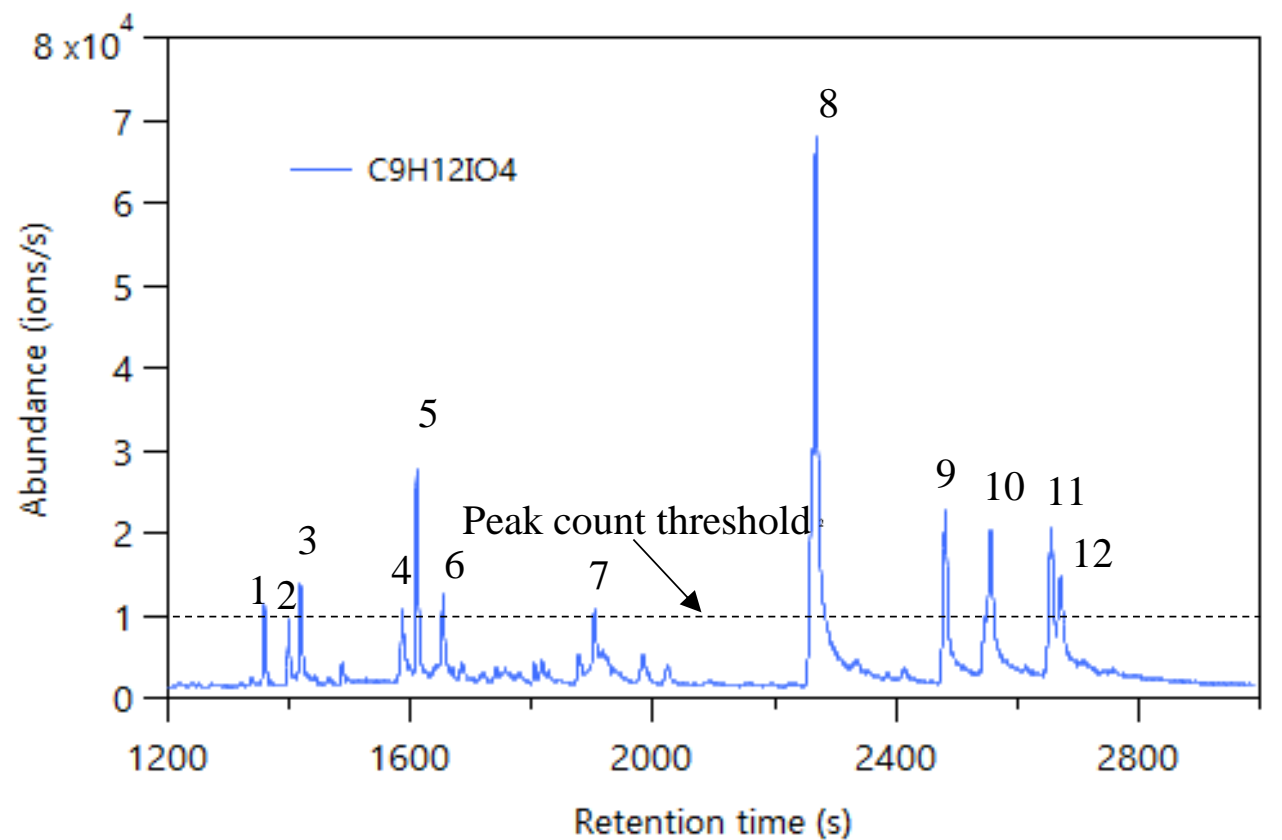

Figure S2. Single ion chromatograph of $\mathrm{C}_{9} \mathrm{H}_{12} \mathrm{IO}_{4}$. Peaks marked with numbers are those having abundance higher than the peak count threshold. 